CLINICAL STUDY

\title{
Insulin gene variable number of tandem repeats is not associated with weight from fetal life until infancy: the Generation R Study
}

\author{
Dennis O Mook-Kanamori ${ }^{1,2}$, J J Miranda Geelhoed ${ }^{1,2}$, Eric A P Steegers ${ }^{3}$, Jacqueline C M Witteman ${ }^{2}$, \\ Albert Hofman ${ }^{2}$, Henriëtte A Moll ${ }^{4}$, Cornelia M van Duijn ${ }^{2}$, Anita C S Hokken-Koelega ${ }^{4}$ \\ and Vincent W V Jaddoe ${ }^{1,2,4}$ \\ ${ }^{1}$ The Generation R Study Group, ${ }^{2}$ Department of Epidemiology and Biostatistics, ${ }^{3}$ Department of Obstetrics and Gynaecology \\ and ${ }^{4}$ Department of Pediatrics, Erasmus Medical Center, PO Box 2040, 3000 CA Rotterdam, The Netherlands \\ (Correspondence should be addressed to VWV Jaddoe; Email: v.jaddoe@erasmusmc.nl)
}

\begin{abstract}
Objective: The aim of this study was to examine whether the insulin gene variable number of tandem repeats (INS VNTR) is associated with growth patterns in fetal life and infancy.

Design and methods: This study was embedded in the Generation R Study, a population-based prospective cohort study from fetal life until young adulthood. Fetal growth was assessed by ultrasounds in early, mid-, and late pregnancy. Anthropometry in infancy was assessed at birth and at the ages of 6 weeks, 6 months, and 14 months. DNA for genotyping of the INS VNTR promoter region was available in 859 children.

Results: The genotype distribution was I/I 50.8\%, I/III 40.0\%, and III/III 9.2\%. III/III individuals had a shorter gestational age $(P<0.005$ versus $\mathrm{I} / \mathrm{I})$ and a lower birth weight $(P<0.05$ versus I/I). There were no differences in birth weight after adjusting for gestational age. Class III homozygotes had a smaller abdominal circumference/head circumference (HC) ratio $(P<0.005$ versus $\mathrm{I} / \mathrm{I})$ in midpregnancy, but not in late pregnancy. Also, III/III subjects had a relative decrease in HC (SDS) from mid-pregnancy to the age of 14 months $(P<0.05$ versus I/I). No other differences in pre- and postnatal growth characteristics and patterns were found.

Conclusions: Class III homozygotes were born at an earlier gestational age. No association was found between INS VNTR and birth weight adjusted for gestational age. Our data suggest that the III/III genotype may be associated with asymmetrical growth in mid-pregnancy, but not in late pregnancy.
\end{abstract}

European Journal of Endocrinology 157 741-748

\section{Introduction}

Insulin is the most important fetal growth factor (1). Previous experimental and observational studies have shown that reduced secretion of fetal insulin and insulinlike growth factors is associated with low birth weight $(1,2)$. Several rare monogenic defects that affect insulin secretion have been shown to be related to altered fetal growth $(1,3)$. It has been suggested that also more common genetic polymorphisms related to insulin secretion and metabolism may explain part of the differences in birth weight in the normal population (3).

Variation at the insulin gene variable number of tandem repeats (INS VNTR) minisatellite has been shown to influence pancreatic insulin gene transcription, both in the fetus and in adulthood $(4,5)$. The VNTR lies upstream of the imprinted insulin and insulin-like growth factor II genes on chromosome $11 \mathrm{p} 15.5$, and has been suggested to influence transcription rate of these genes (5-7). INS VNTR has been suggested as a candidate genetic variant that influences fetal and early postnatal growth in a normal population $(8,9)$. There are two main classes of VNTR, namely class I (30-44 repeat units) and class III (around 150 repeat units); class II is very rare in the Caucasian population (5). Studies in the human pancreas have suggested that INS expression is lower in the VNTR class III homozygous than in the VNTR class I homozygous individuals $(5,10)$. At birth, INS VNTR class III homozygous individuals have been shown to have a larger mean head circumference (HC) (8). Among those subjects without postnatal growth realignment, birth weight and length were also increased (8). However, other cohort studies found a lower birth weight in class III homozygotes or no difference in birth weight at all $(9,11,12)$. It has also been suggested that this genotype is involved in childhood obesity and the development of metabolic syndrome $(13,14)$, polycystic ovary syndrome (15), and type 2 diabetes in adulthood $(16,17)$. Nevertheless, two large cohort studies were unable to 
demonstrate effects of INS VNTR on body composition or the risk of metabolic syndrome in adulthood $(18,19)$.

The inconsistent findings from studies examining the association between INS VNTR genotype with birth size may be explained by the fact that size at birth alone is an inappropriate measure for fetal growth. We hypothesized that variants of the INS VNTR may be stronger related to longitudinally measured growth in pre- and postnatal life than to one specific growth characteristic such as birth weight. Therefore, we examined in the Generation $\mathrm{R}$ Study, a prospective prenatally recruited birth cohort study, the associations of the INS VNTR genotype with growth parameters measured in different periods from fetal life until infancy.

\section{Methods}

\section{Design}

This study was embedded in the Generation R Study, a population-based prospective cohort study from fetal life until young adulthood. This study is designed to identify early environmental and genetic determinants of growth, development, and health from fetal life until young adulthood, and has been described previously in detail $(20,21)$. In total, the cohort includes 9778 mothers and their children living in Rotterdam, the Netherlands. The vast majority $(69 \%)$ of all mothers were enrolled during the first trimester of pregnancy (20). Assessments in pregnancy included physical examinations, fetal ultrasounds, biological samples, and questionnaires. These were planned in early (gestational age $<18$ weeks), mid- (gestational age 18-25 weeks), and late pregnancy (gestational age $>$ 25 weeks) to collect information about fetal growth and its main determinants. Their partners were assessed once during this period. The children were born between April 2002 and January 2006 and from a prenatally recruited birth cohort that is currently being followed until young adulthood. Of all eligible children, $61 \%$ participated in the study at birth. Additionally, more detailed assessments of fetal and postnatal growth and development were conducted in a subgroup of 1232 parents and their children, referred to as the Generation R Focus cohort. This subgroup is completely Caucasian to exclude possible confounding or effect modification by ethnicity. Of all approached women, $80 \%$ were enrolled in this subgroup study in late pregnancy (gestational age of 30 weeks). In this subgroup, postnatal examinations were performed at the ages of 6 weeks, 6 months, and 14 months. The study has been approved by the Medical Ethics Committee of the Erasmus Medical Center, Rotterdam. Written informed consent was obtained from all participants or their parents.

\section{Genotyping INS VNTR gene}

DNA was collected from cord blood samples at birth. Cord blood for DNA isolation was available in $85 \%$ of all children participating in the Focus cohort. Missing cord blood samples were mainly due to logistic constraints at the delivery. PCR was performed to amplify the $-23 / \mathrm{HphI}$ single nucleotide polymorphism (A/T), which is known to be in almost complete linkage disequilibrium with INS VNTR class (22).

The genotype distribution (AA 50.8\%, AT 40.0\%, and TT $9.2 \%$ ) was similar to those found in previous studies and the frequency distribution did not deviate from the HardyWeinberg equilibrium $\left(\chi^{2}=1.28, P>0.1\right)(8,11,19)$.

\section{Fetal growth and birth characteristics}

Fetal ultrasound examinations were carried out in one of the research centers in early, mid-, and late pregnancy. These fetal ultrasounds were used for both establishing gestational age and assessing fetal growth characteristics (23). Pregnancy dating curves were constructed on subjects in the study with complete data on gestational age measured by ultrasound and last menstrual period. Crown-rump length was used for pregnancy dating in early pregnancy (gestational age until 12 weeks and 5 days, crown-rump length smaller than $65 \mathrm{~mm}$ ) and biparietal diameter for pregnancy dating thereafter (gestational age from 12 weeks and 5 days onward, biparietal diameter larger than $20 \mathrm{~mm})(24,25)$. Fetal growth measurements used for the present study included $\mathrm{HC}$, abdominal circumference (AC), and femur length (FL) in mid- and late pregnancy, measured to the nearest millimeter using standardized ultrasound procedures (26). $\mathrm{AC} / \mathrm{HC}$ ratio was calculated, which has been shown to be useful in distinguishing symmetrical from asymmetrical growth (27). Estimated fetal weight was calculated by the Hadlock formula using $\mathrm{HC}, \mathrm{AC}$, and $\mathrm{FL}\left(\log _{10}\right.$ $\mathrm{EFW}=1.5662-0.0108 \quad(\mathrm{HC})+0.0468 \quad(\mathrm{AC})+0.171$ $\left.(\mathrm{FL})+0.00034(\mathrm{HC})^{2}-0.003685(\mathrm{AC} \times \mathrm{FL})\right)(28)$. Early pregnancy was not included since these fetal ultrasound examinations were primarily performed to establish gestational age. Gestational age-adjusted SDS were constructed for all fetal growth measurements. These were based on reference growth charts from the whole study population.

\section{Postnatal growth characteristics}

Date of birth, gender, and birth weight were obtained from community midwife and hospital registries. At the age of 6 weeks, 6 months, and 14 months, anthropometrics were measured without clothes. Weight was measured to the nearest gram using electronic scales. Length was measured in supine position to the nearest millimeter at the ages of 6 weeks and 6 months using a neonatometer, and in upright position at the age of 14 months. HC was measured to the nearest millimeter. 


\section{Covariates}

Information about maternal age, parity, and weight before pregnancy was obtained by the first questionnaire at enrolment in the study. Maternal height was measured without shoes at our research center, and body mass index (weight/height ${ }^{2}\left(\mathrm{~kg} / \mathrm{m}^{2}\right)$ ) was calculated. Information on the occurrence of hypertension, pre-eclampsia, gestational diabetes, and labor details (induced or primary caesarean section, spontaneous) was obtained from midwife and obstetrician records.

\section{Population for analysis}

In total, 1232 women were enrolled in the Generation R Focus Study. Twin pregnancies $(n=15)$ and pregnancies leading to perinatal death $(n=2)$ were excluded from the present analysis. Of the remaining 1215 singleton live births, INS VNTR genotyping was achieved in $71 \%$ $(n=859)$ of the subjects. Growth characteristics in midand late pregnancy and birth weight were available for all these children. In total, 653 (76\%), 653 (76\%) and 605 $(70 \%)$ children participated in the postnatal assessments at the age of 6 weeks, 6 months and 14 months respectively.

\section{Data analysis}

First, differences in maternal, fetal and postnatal characteristics between the INS VNTR genotypic groups were assessed by independent sample $t$-test or Mann-Whitney $U$ test for continuous variables and the $\chi^{2}$ test for categorical variables. Since the insulin and insulin-like growth factor II regions (VNTR-INS-IGF2) are imprinted with their paternally inherited allele being expressed, the I/III heterozygote group can be considered as an indeterminate group, consisting partly of individuals in whom the I allele is expressed and partly of individuals in whom the III allele is expressed. Main interest in our analyses considering etiological associations was on the difference between the I/I and III/III heterozygous subjects. For all analyses, the I/III and III/III genotype groups were both separately compared with the I/I group (reference group). Subsequently, we used multiple linear regression models to assess the associations of INS VNTR with gestational age at birth, adjusting for maternal age, parity, hypertension, pre-eclampsia, gestational diabetes, induced labor, and primary caesarean section. To assess the association without the extremes of gestational age or birth weight, we also performed this analysis, excluding those children born prematurely (gestational age $<37$ weeks) and small or large for gestational age $(-2$ SDS or +2 SDS respectively). Multiple linear regression models were also performed to study the association between genotype and (estimated) weight and $\mathrm{HC}$ and $\mathrm{AC} / \mathrm{HC}$ ratio at each age cross-sectionally (prenatally: mid- and late pregnancy, at birth; postnatally: 6 weeks, 6 months, and 14 months). These models were adjusted for gender and age, and postnatal data were additionally adjusted for gestational age at birth. Next, to examine the associations of INS VNTR with prospectively measured growth patterns, rather than growth characteristics at one age, we studied the differences in (estimated) weight change (SDS) and HC (SDS) change from mid-pregnancy to 14 months between genotypes using multiple linear regression models. Since it has been suggested that in children from multiparous mothers and/or in children with no postnatal growth realignment, the genetic contribution to birth weight is greater than that in the firstborn, and/or in children with growth realignment, we also examined the associations of INS VNTR genotype and birth weight in strata of birth order and growth realignment (6). As described previously, growth realignment was defined as a change, either increase or decrease, in weight, between birth and 14 months, of more than 0.67 SDS ('changers' means, for example, a 3rd to 10th percentile increase, and 'nonchangers' means a growth realignment $<0.67$ SDS) $(8$, 17, 29). Finally, using Pearson's $\chi^{2}$, we compared the prevalence of catch-up growth between genotypes, where catch-up growth was defined as a positive growth realignment of more than 0.67 SDS.

All effect estimates are presented with their 95\% confidence interval (CI). Statistical analyses were performed using the Statistical Package of Social Sciences version 11.0 for Windows (SPSS Inc., Chicago, IL, USA).

\section{Results}

Subject characteristics for the three genotypes are shown in Tables 1-3. Genotype frequency distribution was I/I $50.8 \%$, I/III $40.0 \%$, and III/III 9.2\%. No differences between genotypes were found in maternal characteristics. Gender distribution was similar in the three genotypes. In mid-pregnancy, class III homozygotes had

Table 1 Maternal characteristics according to fetal insulin gene variable number of tandem repeats (VNTR) class genotype.

\begin{tabular}{|c|c|c|c|}
\hline & $\begin{array}{c}\mathbf{I} / \mathbf{I} \\
(n=436)\end{array}$ & $\begin{array}{c}\text { I/III } \\
(n=344)\end{array}$ & $\begin{array}{c}\text { III/III } \\
(n=79)\end{array}$ \\
\hline \multicolumn{4}{|l|}{ Maternal characteristics } \\
\hline Age (years) & $31.7(4.1)$ & 31.5 (4.3) & $31.5(4.0)$ \\
\hline Weight (kg) & $68.6(11.9)$ & $69.1(13.1)$ & $69.0(12.3)$ \\
\hline Height (cm) & $171.0(6.6)$ & $171.1(6.4)$ & $170.6(6.2)$ \\
\hline $\begin{array}{l}\text { Body mass index } \\
\left(\mathrm{kg} / \mathrm{m}^{2}\right)\end{array}$ & $23.4(3.9)$ & $23.6(4.1)$ & $23.7(3.9)$ \\
\hline Parity (\% nulliparous) & $59.1 \%$ & $59.9 \%$ & $59.0 \%$ \\
\hline Hypertension (\%) & $5.1 \%$ & $4.4 \%$ & $7.7 \%$ \\
\hline Pre-eclampsia (\%) & $1.2 \%$ & $1.2 \%$ & $1.3 \%$ \\
\hline Gestational diabetes (\%) & $0.2 \%$ & $1.2 \%$ & $1.3 \%$ \\
\hline Induced labor (\%) & $26.2 \%$ & $24.1 \%$ & $34.2 \%$ \\
\hline $\begin{array}{l}\text { Primary caesarean } \\
\text { section (\%) }\end{array}$ & $3.1 \%$ & $3.1 \%$ & $5.1 \%$ \\
\hline
\end{tabular}

Values are means (SDS) or percentages. Differences were tested using independent sample $t$-test or $\chi^{2}$ test. Of the total group, data were missing in maternal height before pregnancy $(n=8)$, weight and body mass index $(n=146)$, parity $(n=12)$, hypertension $(n=4)$, pre-eclampsia $(n=4)$, gestational diabetes $(n=5)$, induced labor $(n=35)$, and primary caesarean section $(n=42)$. 
Table 2 Fetal characteristics according to fetal insulin gene variable number of tandem repeats (VNTR) class genotype.

\begin{tabular}{lccc}
\hline & $\mathrm{I} / \mathrm{I}(n=436)$ & $\mathrm{I} / \mathrm{III}(n=344)$ & III/III $(n=79)$ \\
\hline Fetal characteristics mid-pregnancy & & & \\
Gestational age (weeks) & $20.6(1.0)$ & $20.5(1.0)$ & $20.4(0.9)$ \\
Head circumference $(\mathrm{mm})$ & $179(12.6)$ & $178(12.8)$ & $178(11.0)$ \\
Abdominal circumference (mm) & $157(13.1)$ & $156(13.1)$ & $154(12.0)^{\star}$ \\
Femur length (mm) & $33.1(3.1)$ & $32.9(3.1)$ & $32.6(3.0)$ \\
Abdominal/head circumference ratio & $0.880(0.043)$ & $0.880(0.040)$ & $0.865(0.035)^{\dagger}$ \\
Estimated fetal weight (g) & $377(80)$ & $371(80)$ & $359(69)$ \\
Fetal characteristics late pregnancy & & $30.4(1.0)$ & $30.5(1.0)$ \\
Gestational age (weeks) & $30.4(1.0)$ & $286(11.7)$ & $287(13.0)$ \\
Head circumference (mm) & $286(11.7)$ & $267(16.7)$ & $267(18.0)$ \\
Abdominal circumference (mm) & $265(15.7)$ & $57.4(2.9)$ & $57.3(2.8)$ \\
Femur length (mm) & $57.1(3.1)$ & $0.933(0.044)$ & $0.931(0.046)$ \\
Abdominal/head circumference ratio & $0.928(0.042)$ & $1648(261)$ & $1648(267)$ \\
Estimated fetal weight (g) & $1622(255)$ & \\
\hline
\end{tabular}

Values are means (SDS). Differences were tested using independent sample $t$-test. Of the total group, data were missing in mid-pregnancy gestational age ( $n=10)$, head circumference $(n=14)$, abdominal circumference $(n=12)$, femur length $(n=14)$, abdominal circumference/head circumference ratio $(n=36)$, estimated fetal weight $(n=16)$, late pregnancy gestational age $(n=6)$, head circumference $(n=8)$, abdominal circumference $(n=10)$, femur length $(n=9)$, abdominal circumference/head circumference ratio $(n=22)$, and estimated fetal weight $(n=10)$.

${ }^{\star} P<0.05$ versus $\mathrm{I} / /$ genotype; ${ }^{\dagger} P<0.005$ versus $\mathrm{I} / / \mathrm{I}$ genotype.

a smaller $\mathrm{AC}$ and a reduced $\mathrm{AC} / \mathrm{HC}$ compared with class I homozygotes. Subjects with the III/III genotype were born at a significantly shorter gestational age and had a lower birth weight than the I/I individuals. After adjusting for maternal age, parity, hypertension, preeclampsia, gestational diabetes, induced labor, and primary caesarean section, gestational age remained shorter in the homozygous III/III group (differences: -0.39 (95\% CI: $-0.71,-0.08)$ weeks versus I/I). Also, when we excluded large and small for gestational age births and preterm births from the analysis, the difference in gestational age was significant (differences: -0.34 (95\% CI: $-0.62,-0.05)$ weeks versus I/I). The odds ratio for preterm birth in the III/III group

Table 3 Birth and postnatal characteristics according to insulin gene variable number of tandem repeats (VNTR) class genotype.

\begin{tabular}{|c|c|c|c|}
\hline & $\mathrm{I} / \mathrm{I}(n=436)$ & $\mathbf{I} / \mathrm{III}(n=344)$ & III/III $(n=79)$ \\
\hline \multicolumn{4}{|l|}{ Birth } \\
\hline Gestational age (weeks) & $40.2(36.7-42.4)$ & $40.2(37.6-42.4)$ & $39.6(36.0-42.3)^{\star}$ \\
\hline Gestational age $<37$ weeks (\%) & $3.0 \%$ & $1.7 \%$ & $5.1 \%$ \\
\hline Weight $(\mathrm{g})$ & $3510(512)$ & $3591(478)$ & $3396(504)^{\dagger}$ \\
\hline Weight (SDS) & $0.01(0.99)$ & $0.14(0.98)$ & $-0.01(0.90)$ \\
\hline Weight $<-2$ SDS (\%) & $3.2 \%$ & $2.3 \%$ & $2.5 \%$ \\
\hline Weight $>+2$ SDS (\%) & $2.1 \%$ & $3.2 \%$ & $1.3 \%$ \\
\hline Gender (\% boy) & $50.0 \%$ & $55.2 \%$ & $50.6 \%$ \\
\hline \multicolumn{4}{|l|}{ Postnatal characteristics 6 weeks } \\
\hline Age at visit (weeks) & $6.9(4.6-12.7)$ & $6.5(4.4-10.3)$ & $7.1(4.2-14.9)$ \\
\hline Head circumference $(\mathrm{cm})$ & $38.6(1.4)$ & $38.6(1.4)$ & $38.5(1.8)$ \\
\hline Weight $(\mathrm{g})$ & $4919(710)$ & $4918(615)$ & 4817 (802) \\
\hline Length $(\mathrm{cm})$ & $56.7(2.6)$ & $57.0(2.4)$ & $56.3(2.8)$ \\
\hline Body mass index $\left(\mathrm{kg} / \mathrm{m}^{2}\right)$ & $15.2(1.5)$ & $15.1(1.4)$ & $15.1(1.4)$ \\
\hline \multicolumn{4}{|l|}{ Postnatal characteristics 6 months } \\
\hline Age at visit (weeks) & $27.7(23.3-34.3)$ & $28.4(23.7-36.4)$ & $28.3(24.1-35.6)$ \\
\hline Head circumference $(\mathrm{cm})$ & $43.8(1.3)$ & $44.0(1.3)$ & $43.9(1.7)$ \\
\hline Weight $(\mathrm{g})$ & 7889 (859) & 7998 (897) & 7878 (907) \\
\hline Length $(\mathrm{cm})$ & $68.4(2.6)$ & $69.0(2.7)$ & $68.6(2.7)$ \\
\hline Body mass index $\left(\mathrm{kg} / \mathrm{m}^{2}\right)$ & $16.8(1.3)$ & $16.8(1.3)$ & $16.8(1.5)$ \\
\hline \multicolumn{4}{|l|}{ Postnatal characteristics 14 months } \\
\hline Age at visit (months) & $14.7(13.4-17.5)$ & $14.5(13.3-16.5)$ & $14.6(13.5-17.3)$ \\
\hline Head circumference $(\mathrm{cm})$ & $47.3(1.4)$ & $47.4(1.3)$ & $47.0(1.6)$ \\
\hline Weight (g) & $10490(1074)$ & $10563(1053)$ & $10431(1181)$ \\
\hline Length $(\mathrm{cm})$ & $79.1(2.9)$ & $79.3(3.0)$ & $78.8(3.2)$ \\
\hline Body mass index $\left(\mathrm{kg} / \mathrm{m}^{2}\right)$ & $16.8(1.3)$ & $16.8(1.1)$ & $16.8(1.2)$ \\
\hline
\end{tabular}

Values are means (SDS), medians (95\% range) for variables with skewed distribution, or percentages. Differences were tested using independent sample $t$-test, Mann-Whitney Utest, or $\chi^{2}$ test. Of the total group, data were missing at 6 weeks head circumference $(n=242)$, weight $(n=232)$, and length ( $\left.n=235\right)$; at 6 months head circumference $(n=234)$, weight $(n=230)$, and length $(n=232)$; and at 14 months head circumference $(n=293)$, weight $(n=262)$, and length $(n=270)$. ${ }^{*} P<0.005$ versus $\mathrm{I} / \mathrm{I}$ genotype; ${ }^{\dagger} P<0.05$ versus $\mathrm{I} / \mathrm{l}$ genotype. 


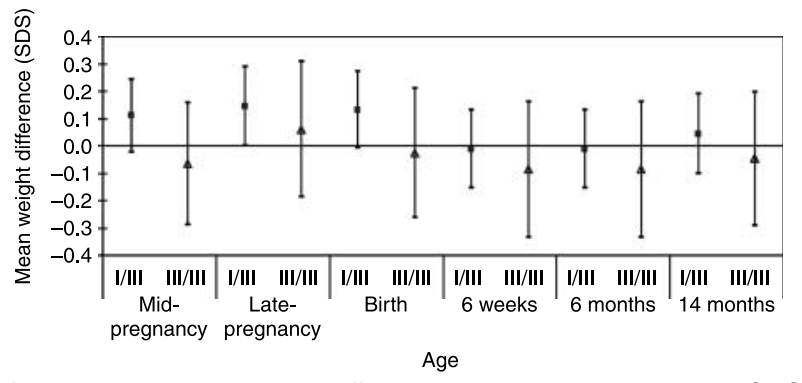

Figure 1 Values represent differences between genotypes in SDS (95\% confidence interval) based on multiple linear regression models, adjusted for (gestational) age and gender. Postnatal estimates are additionally adjusted for gestational age at birth.

versus the I/I group was not significant (1.86 (95\% CI: $0.58,5.94)$ ). No differences in birth weight SDS were found.

Results from the cross-sectional multiple regression analyses of weight, $\mathrm{HC}$, and $\mathrm{AC} / \mathrm{HC}$ ratio (prenatal) at each age are shown in Figs 1-3. No differences in weight (SDS) were found at any age. In class III homozygous subjects, HC (SDS) tended to be larger in mid-pregnancy and smaller at the age of 14 months compared with class I homozygotes (differences: 0.23 (95\% CI: $0.00,0.46)$ SDS and -0.25 (95\% CI: -0.49 , 0.00) SDS respectively), though these differences were not significant. $\mathrm{AC} / \mathrm{HC}$ ratio was significantly lower in the III/III subjects than in the I/I individuals in midpregnancy (difference: -0.28 (95\% CI: $-0.47,-0.09)$ SDS), but not in late pregnancy.

From mid-pregnancy to 14 months, the III/III individuals had a significant mean decrease in HC SDS compared with the I/I subjects (Table 4). No difference between the genotype groups in weight change were found during any period between mid-pregnancy and the age of 14 months.

The associations between INS VNTR genotypes and birth weight, stratified by birth order and weight realignment, are shown in Table 5. Among the firstborn children, subjects with the I/III genotype were significantly heavier than the I/I individuals. Birth weight was similar in the three genotype groups among children born to multiparous mothers. No difference between the three genotypes was found in birth weight

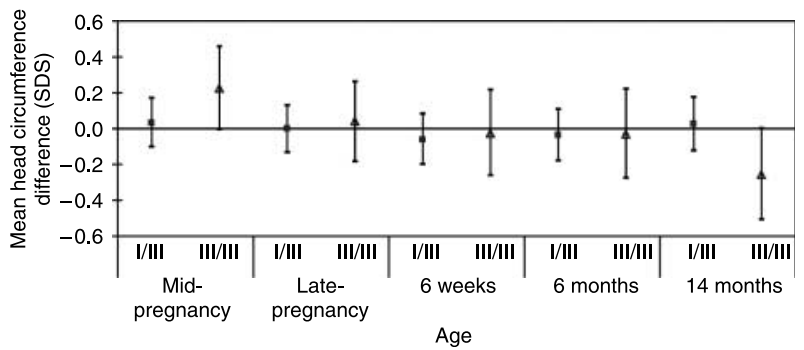

Figure 2 Values represent differences between genotypes in SDS (95\% confidence interval) based on multiple linear regression models, adjusted for (gestational) age and gender. Postnatal estimates are additionally adjusted for gestational age at birth.

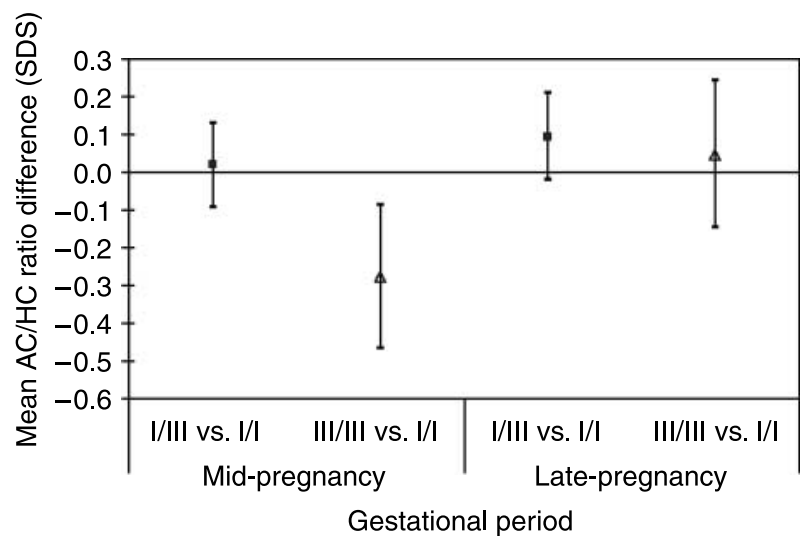

Figure 3 Values represent differences between genotypes in SDS (95\% confidence interval) based on multiple linear regression models, adjusted for gestational age and gender.

among the 'non-changers'. Among the 'changers', however, the I/III subjects had a significantly higher birth weight than the I/I subjects after adjusting for age and gender. And finally, no differences were found between the three genotypes in the prevalence of catchup growth between birth and the age of 14 months $\left(P>0.5\right.$, using Pearson's $\left.\chi^{2}\right)$.

\section{Discussion}

We showed that the III/III individuals of INS VNTR had a shorter gestational duration compared with the I/I subjects. No differences were found in birth weight adjusted for gestational age. Class III homozygous subjects had a smaller AC/HC ratio in mid-pregnancy but not in late pregnancy, compared with the I/I individuals. In III/III, we also found a decreased growth rate in $\mathrm{HC}$ from mid-pregnancy to 14 months of age. No differences were found for any other growth characteristics or patterns.

To our knowledge, this study is the first prospective cohort that examined the associations between INS VNTR and growth in fetal life and infancy. DNA for genotyping was available in 859 Caucasian subjects $(71 \%)$, and of all genotyped subjects at baseline, about $70-75 \%$ participated in the follow-up measurements in infancy. Children who were not genotyped had a shorter gestational age at birth (difference: -0.47 (95\% CI: $-0.72,-0.21)$ weeks, $P<0.001)$ and a lower birth weight (difference: -52.2 (95\% CI: $-143.7,39.6) \mathrm{g}$, $P=0.18$ ). Our effect estimates would be biased if the associations between INS VNTR genotype and growth characteristics differ between those with and without complete data. This seems unlikely but cannot be excluded.

The underlying mechanism explaining how INS VNTR influences growth remains unclear. In the pancreas, INS expression has been found to be lower in the VNTR class III homozygous than in the VNTR 
Table 4 Differences in weight change (SDS) and head circumference (SDS) change from mid-pregnancy to 14 months using the I/l genotype as a reference group.

\begin{tabular}{lcc}
\hline Genotype & Weight change (SDS) & Head circumference change (SDS) \\
\hline $\mathrm{I} / \mathrm{I}$ & Reference & Reference \\
$\mathrm{I} / \mathrm{III}$ & $-0.083(-0.292,0.127)$ & $-0.027(-0.236,0.181)$ \\
$\mathrm{III} / \mathrm{II}$ & $-0.029(-0.378,0.320)$ & $-0.443(-0.799,-0.086)^{\star}$ \\
\hline
\end{tabular}

Values represent differences in change in SDS (95\% confidence interval). Differences were tested using multiple linear regression models.

${ }^{\star} P<0.05$ versus $\mathrm{I} / \mathrm{I}$ genotype.

class I homozygous subjects $(5,10)$. It has also been hypothesized that the VNTR influences IGF2, a neighboring gene on chromosome 11p15.5 (8, 10), though studies have been conflicting. The VNTR class I allele is associated with higher IGF2 expression in the human placenta (7), while VNTR class III homozygotes have been shown to have higher IGF-II cord blood levels (6). INS and IGF2 are both imprinted genes (30). In the human yolk sac, INS has been shown to be exclusively paternally expressed (30), and the imprinting of the IGF 2/H19 region is known to affect growth in syndromes with early growth disorders (31). Therefore, several studies have focused on paternal-specific allele transmission of the VNTR-INS-IGF2 region in relation to growth and diseases. Paternally derived VNTR class III allele has been shown to be associated with type 2 diabetes (16) and polycystic ovary syndrome (32), while paternally derived VNTR class I allele may be a risk factor for childhood obesity (33). These findings suggest that the greatest phenotypic difference would be between class I and III homozygous individuals, since, by definition, they have inherited an active paternal allele. Other studies however, show no parent-of-origin effect on birth weight or type 2 diabetes $(6,9)$. Finally, Igf2 in mice plays an important role in placental development and regulation (34). The VNTR may affect the imprinting of Igf 2 and subsequently impair placental circulation (34).

Several studies have examined the association between INS VNTR and growth. In the Avon Longitudinal Study of Parents and Children cohort, Dunger et al. was the first to show an association between INS VNTR and birth size (8). In those individuals who had no postnatal weight realignment and in children from multiparous mothers, class III genotype was associated with a larger birth size $(6,8)$. It has been proposed that in these children the maternal uterine factors are less important and the genetic contribution to growth is amplified (8). On the other hand, in a Pima Indian population, class III genotype was associated with lower birth weight and an increased prevalence of type 2 diabetes (9). Two other studies, one of which was performed in a large Finnish cohort, could not replicate any of the results regarding birth weight, also after stratifying for postnatal realignment $(11,12)$.

In our study, we found no differences in weight in fetal life, at birth or in infancy. We also did not find associations between patterns in weight gain from fetal life until infancy. Unexpectedly, class III homozygous subjects had a shorter gestational age at birth than class I homozygous subjects. No such association has been described previously. This difference remained significant after adjusting for factors that may explain a shorter gestational period, such as birth weight and pregnancy and delivery complications. Furthermore, this association was still present after excluding all large and small for gestational age births and preterm births, and therefore cannot be explained by outliers or skewed distributions. We have no explanation for this finding. It could be hypothesized that altered intra-uterine growth patterns resulting in earlier maturation or changes in placental function may cause an earlier delivery. However, this association remained significant after adjustment for birth weight. Also, additional adjustment for weight change between 20 weeks and birth did not materially affect our effect estimate (results not shown). On the other hand, this association turned up without a previous hypothesis. Therefore, this finding could be due to chance, and further studies in other populationbased cohorts are needed for replication.

Class III genotype subjects also had a considerably smaller $\mathrm{AC} / \mathrm{HC}$ ratio in mid-pregnancy. We found that class III homozygote subjects tended to have a larger $\mathrm{HC}$ and a smaller AC in mid-pregnancy. However, by late pregnancy, HC SDS was decreased and AC SDS was

Table 5 Birth weight per genotype, stratified by birth order and growth realignment.

\begin{tabular}{lcc|cc}
\hline Genotype & 1st pregnancy & 2nd+ pregnancy & Non-changers & Changers \\
\hline I/I & $3421(516)$ & $3633(476)$ & $3498(413)$ & $3555(541)$ \\
I/III & $3512(490)^{*}$ & $3668(449)$ & $3510(421)$ & $3695(493)^{*}$ \\
III/III & $3398(502)$ & $3616(467)$ & $3462(524)$ & $3463(526)$ \\
\hline
\end{tabular}

Values represent mean in grams (SDS). Differences were tested using multiple linear regression models, adjusting for gestational age and gender. Change is defined as postnatal growth realignment between birth and 14 months, positive or negative, of more than 0.67 SDS.

${ }^{*} P<0.05$ versus $\mathrm{I} / \mathrm{I}$ genotype. 
increased in these fetuses, resulting in a similar $\mathrm{AC} / \mathrm{HC}$ ratio as class $\mathrm{I} / \mathrm{I}$ subjects. $\mathrm{AC} / \mathrm{HC}$ ratio has been shown to be useful in distinguishing symmetrical from asymmetrical growth (27). Asymmetrical growth with a relatively large $\mathrm{HC}$ is also known as brain sparing. Our findings may suggest that brain sparing occurs in early pregnancy in these individuals. On the basis of current literature, we did not hypothesize beforehand to find such an association specifically. Therefore, further studies are necessary to replicate these findings.

Epidemiological studies have demonstrated an inverse relationship between birth weight and the risk of developing type 2 diabetes and cardiovascular disease in adulthood $(35,36)$. The fetal insulin hypothesis proposes that genetic variants that regulate fetal insulin or sensitivity may lead to both impaired fetal growth and increased morbidity in later life (3). Several studies, however, have suggested that rather than low birth weight per se it is postnatal accelerated weight gain in subjects with a small size at birth, that leads to a normal or increasing weight from childhood onward, increasing the risk for adult disease (37-39). Animal models have shown that an altered fetal growth trajectory may also lead to an increased risk of adult morbidity, even when birth weight is normal (40). We only found differences in early fetal growth patterns between INS VNTR genotype variants. In our study, postnatal growth characteristics were available until the age of 14 months. Studies with a longer followup period are needed to assess whether this genotype is associated with growth patterns in childhood, which are related to the development of type 2 diabetes and cardiovascular disease in adulthood. It has also been suggested that prematurity, regardless of birth weight, can lead to reduced insulin sensitivity and possibly type 2 diabetes in later life (41). Our finding that shows an association between INS VNTR and gestational age is in line with the hypothesis that common genetic variations may underlie the association between preterm birth and increased risk of development of type 2 diabetes and cardiovascular disease.

In conclusion, this study demonstrates that INS VNTR is not associated with weight from fetal life until infancy. Our data suggest that INS VNTR is associated with asymmetrical growth in early and mid-pregnancy, but not in late pregnancy. We found for the first time an association between INS VNTR and gestational age at birth. Studies in larger cohorts are necessary to replicate our findings. Also, systematic searches by genome-wide association studies may enable us to obtain a more complete understanding of the functionality of the entire VNTR-INS-IGF2 region and its relation to growth and morbidity in childhood and later life.

\section{Acknowledgements}

The Generation R Study is conducted by the Erasmus Medical Center in close collaboration with the School of Law and Faculty of Social Sciences of the Erasmus University Rotterdam, the Municipal Health Service Rotterdam area, Rotterdam, the Rotterdam Homecare Foundation, Rotterdam, and the Stichting Trombosedienst \& Artsenlaboratorium Rijnmond (STAR), Rotterdam. We gratefully acknowledge the contribution of general practitioners, hospitals, midwives, and pharmacies in Rotterdam. The first phase of the Generation R Study is made possible by the financial support from the Erasmus Medical Center, Rotterdam, the Erasmus University Rotterdam, and the Netherlands Organization for Health Research and Development (ZonMw). The study described in this paper was made possible by an additional grant from the Netherlands Organization for Health Research and Development (ZonMw, grant no. 2100.0074) and the National Diabetic Fund (grant no. 2002.00.035).

\section{References}

1 Hay WW Jr. Recent observations on the regulation of fetal metabolism by glucose. Journal of Physiology 2006572 17-24.

2 Fowden AL. The insulin-like growth factors and feto-placental growth. Placenta 200324 803-812.

3 Hattersley AT \& Tooke JE. The fetal insulin hypothesis: an alternative explanation of the association of low birthweight with diabetes and vascular disease. Lancet 1999353 1789-1792.

4 Bennett ST, Wilson AJ, Cucca F, Nerup J, Pociot F, McKinney PA, Barnett AH, Bain SC \& Todd JA. IDDM2-VNTR-encoded susceptibility to type 1 diabetes: dominant protection and parental transmission of alleles of the insulin gene-linked minisatellite locus. Journal of Autoimmunity 19969 415-421.

5 Vafiadis P, Bennett ST, Colle E, Grabs R, Goodyer CG \& Polychronakos C. Imprinted and genotype-specific expression of genes at the IDDM2 locus in pancreas and leucocytes. Journal of Autoimmunity 1996 9 397-403.

6 Ong KK, Petry CJ, Barratt BJ, Ring S, Cordell HJ, Wingate DL, Pembrey ME, Todd JA \& Dunger DB. Maternal-fetal interactions and birth order influence insulin variable number of tandem repeats allele class associations with head size at birth and childhood weight gain. Diabetes 200453 1128-1133.

7 Paquette J, Giannoukakis N, Polychronakos C, Vafiadis P \& Deal C. The INS $5^{\prime}$ variable number of tandem repeats is associated with IGF2 expression in humans. Journal of Biological Chemistry 1998 273 14158-14164.

8 Dunger DB, Ong KK, Huxtable SJ, Sherriff A, Woods KA, Ahmed ML, Golding J, Pembrey ME, Ring S, Bennett ST \& Todd JA. Association of the INS VNTR with size at birth. ALSPAC Study Team. Avon longitudinal study of pregnancy and childhood. Nature Genetics 199819 98-100.

9 Lindsay RS, Hanson RL, Wiedrich C, Knowler WC, Bennett PH \& Baier LJ. The insulin gene variable number tandem repeat class I/III polymorphism is in linkage disequilibrium with birth weight but not Type 2 diabetes in the Pima population. Diabetes 200352 187-193.

10 Kennedy GC, German MS \& Rutter WJ. The minisatellite in the diabetes susceptibility locus IDDM 2 regulates insulin transcription. Nature Genetics 19959 293-298.

11 Mitchell SM, Hattersley AT, Knight B, Turner T, Metcalf BS, Voss LD, Davies D, McCarthy A, Wilkin TJ, Smith GD, Ben-Shlomo Y \& Frayling TM. Lack of support for a role of the insulin gene variable number of tandem repeats minisatellite (INS-VNTR) locus in fetal growth or type 2 diabetes-related intermediate traits in United Kingdom populations. Journal of Clinical Endocrinology and Metabolism 200489 310-317. 
12 Bennett AJ, Sovio U, Ruokonen A, Martikainen H, Pouta A, Taponen S, Hartikainen AL, King VJ, Elliott P, Jarvelin MR \& McCarthy MI. Variation at the insulin gene variable number tandem repeat (VNTR) polymorphism and early growth: studies in a large Finnish birth cohort. Diabetes $2004532126-2131$.

13 Le Stunff C, Fallin D, Schork NJ \& Bougneres P. The insulin gene VNTR is associated with fasting insulin levels and development of juvenile obesity. Nature Genetics 200026 444-446.

14 Santoro N, Cirillo G, Amato A, Luongo C, Raimondo P, D’Aniello A, Perrone L \& Miraglia del Giudice E. Insulin gene variable number of tandem repeats (INS VNTR) genotype and metabolic syndrome in childhood obesity. Journal of Clinical Endocrinology and Metabolism $2006914641-4644$.

15 Waterworth DM, Bennett ST, Gharani N, McCarthy MI, Hague S, Batty S, Conway GS, White D, Todd JA, Franks S \& Williamson R. Linkage and association of insulin gene VNTR regulatory polymorphism with polycystic ovary syndrome. Lancet 1997 349 986-990.

16 Huxtable SJ, Saker PJ, Haddad L, Walker M, Frayling TM, Levy JC, Hitman GA, O'Rahilly S, Hattersley AT \& McCarthy MI. Analysis of parent-offspring trios provides evidence for linkage and association between the insulin gene and type 2 diabetes mediated exclusively through paternally transmitted class III variable number tandem repeat alleles. Diabetes 200049 126-130.

17 Ong KK, Phillips DI, Fall C, Poulton J, Bennett ST, Golding J, Todd JA \& Dunger DB. The insulin gene VNTR, type 2 diabetes and birth weight. Nature Genetics $199921262-263$.

18 Bennett A, Sovio U, Ruokonen A, Martikainen H, Pouta A, Taponen S, Hartikainen AL, Franks S, Peltonen L, Elliott P, Jarvelin MR \& McCarthy MI. No association between insulin gene variation and adult metabolic phenotypes in a large Finnish birth cohort. Diabetologia $2005 \mathbf{4 8} 886-891$.

19 Sandhu MS, Heude B, Young EH, Luben R, Luan J, Khaw KT, Todd J \& Wareham NJ. INS VNTR class genotype and indexes of body size and obesity: population-based studies of 7999 middleaged men and women. Diabetes $2005 \mathbf{5 4} 2812-2815$.

20 Jaddoe VW, Mackenbach JP, Moll HA, Steegers EA, Tiemeier H, Verhulst FC, Witteman JC \& Hofman A. The Generation R Study: design and cohort profile. European Journal of Epidemiology 2006 21 475-484.

21 Hofman A, Jaddoe VW, Mackenbach JP, Moll HA, Snijders RF, Steegers EA, Verhulst FC, Witteman JC \& Buller HA. Growth, development and health from early fetal life until young adulthood: the Generation $\mathrm{R}$ Study. Paediatric and Perinatal Epidemiology 200418 61-72.

22 Stead JD \& Jeffreys AJ. Structural analysis of insulin minisatellite alleles reveals unusually large differences in diversity between Africans and non-Africans. American Journal of Human Genetics 200271 1273-1284.

23 Tunon K, Eik-Nes SH \& Grottum P. A comparison between ultrasound and a reliable last menstrual period as predictors of the day of delivery in 15000 examinations. Ultrasound Obstetrics and Gynecology 19968 178-185.

24 Robinson HP, Sweet EM \& Adam AH. The accuracy of radiological estimates of gestational age using early fetal crown-rump length measurements by ultrasound as a basis for comparison. British Journal of Obstetrics and Gynaecology 197986 525-528.

25 Altman DG \& Chitty LS. New charts for ultrasound dating of pregnancy. Ultrasound Obstetrics and Gynecology $1997 \mathbf{1 0}$ 174-191.

26 Routine ultrasound screening in pregnancy: protocol RCOG. London, UK: RCOG Press, 2000.
27 Campbell S \& Thoms A. Ultrasound measurement of the fetal head to abdomen circumference ratio in the assessment of growth retardation. British Journal of Obstetrics and Gynaecology $1977 \mathbf{8 4}$ 165-174.

28 Hadlock FP, Harrist RB, Carpenter RJ, Deter RL \& Park SK. Sonographic estimation of fetal weight. The value of femur length in addition to head and abdomen measurements. Radiology 1984 150 535-540.

29 Ong KK, Ahmed ML, Emmett PM, Preece MA \& Dunger DB. Association between postnatal catch-up growth and obesity in childhood: prospective cohort study. BMJ $2000320967-971$.

30 Moore GE, Abu-Amero SN, Bell G, Wakeling EL, Kingsnorth A, Stanier P, Jauniaux E \& Bennett ST. Evidence that insulin is imprinted in the human yolk sac. Diabetes 200150 199-203.

31 Gicquel C, Rossignol S, Cabrol S, Houang M, Steunou V, Barbu V, Danton F, Thibaud N, Le Merrer M, Burglen L, Bertrand AM, Netchine I \& Le Bouc Y. Epimutation of the telomeric imprinting center region on chromosome 11p15 in Silver-Russell syndrome. Nature Genetics 200537 1003-1007.

32 Michelmore K, Ong K, Mason S, Bennett S, Perry L, Vessey M, Balen A \& Dunger D. Clinical features in women with polycystic ovaries: relationships to insulin sensitivity, insulin gene VNTR and birth weight. Clinical Endocrinology 200155 439-446.

33 Le Stunff C, Fallin D \& Bougneres P. Paternal transmission of the very common class I INS VNTR alleles predisposes to childhood obesity. Nature Genetics 200129 96-99.

34 Fowden AL, Sibley C, Reik W \& Constancia M. Imprinted genes, placental development and fetal growth. Hormone Research 2006 65 50-58.

35 McMillen IC \& Robinson JS. Developmental origins of the metabolic syndrome: prediction, plasticity, and programming. Physiological Reviews 200585 571-633.

36 Hovi P, Andersson S, Eriksson JG, Jarvenpaa AL, StrangKarlsson S, Makitie O \& Kajantie E. Glucose regulation in young adults with very low birth weight. New England Journal of Medicine $20073562053-2063$.

37 Bateson P, Barker D, Clutton-Brock T, Deb D, D’Udine B, Foley RA, Gluckman P, Godfrey K, Kirkwood T, Lahr MM, McNamara J, Metcalfe NB, Monaghan P, Spencer HG \& Sultan SE. Developmental plasticity and human health. Nature $2004 \mathbf{4 3 0} 419-421$.

38 Mericq V, Ong KK, Bazaes R, Pena V, Avila A, Salazar T, Soto N, Iniguez G \& Dunger DB. Longitudinal changes in insulin sensitivity and secretion from birth to age three years in smalland appropriate-for-gestational-age children. Diabetologia 2005 48 2609-2614.

39 Law CM, Shiell AW, Newsome CA, Syddall HE, Shinebourne EA, Fayers PM, Martyn CN \& de Swiet M. Fetal, infant, and childhood growth and adult blood pressure: a longitudinal study from birth to 22 years of age. Circulation $2002 \mathbf{1 0 5} 1088-1092$.

40 Bloomfield FH, Oliver MH \& Harding JE. The late effects of fetal growth patterns. Archives of Disease in Childhood. Fetal and Neonatal Edition 200691 F299-F304.

41 Hofman PL, Regan F, Jackson WE, Jefferies C, Knight DB, Robinson EM \& Cutfield WS. Premature birth and later insulin resistance. New England Journal of Medicine 2004351 2179-2186.

Received 17 August 2007

Accepted 25 September 2007 